\title{
A IMPORTÂNCIA DA ASSISTÊNCIA TÉCNICA E EXTENSÃO RURAL A PRODUTORES DE BASE FAMILIAR
}

\author{
Michele da Rosa Scholant Simões ${ }^{1}$
}

\begin{abstract}
RESUMO: Este trabalho apresenta a importância da assistência técnica e extensão rural a produtores de base familiar. Foi possível constatar que a adoção de um novo modelo de desenvolvimento pelo Brasil, e a consequente criação e aumento de políticas públicas voltadas para a inclusão e a promoção do desenvolvimento rural sustentável, para o agricultor familiar. Com o objetivo de avaliar o efeito da utilização de assistência técnica sobre a renda mensal dos agricultores familiares. A qualidade dos alimentos orgânicos, tornando-se essencial para o acesso ao mercado consumidor e para garantir a credibilidade desses produtos e, assim, consolidar a agricultura orgânica como instrumento para o desenvolvimento da agricultura familiar. Neste sentindo, ainda têm diversos desafios para o desenvolvimento rural. A expansão da política, associada às análises sistêmicas para seu constante aperfeiçoamento, é, deste modo, um caminho promissor para o desenvolvimento econômico da agricultura familiar no Brasil.
\end{abstract}

Palavras-chave: Agricultura familiar. Desenvolvimento rural. Políticas públicas.

ABSTRACT: This work presents the importance of technical assistance and rural extension to family-based producers. It was possible to verify that the adoption of a new development model by Brazil, and the consequent creation and increase of public policies aimed at the inclusion and promotion of sustainable rural development, for the family farmer. In order to evaluate the effect of using technical assistance on the monthly income of family farmers. The quality of organic food, becoming essential for access to the consumer market and to ensure the credibility of these products and, thus, consolidate organic agriculture as an instrument for the development of family farming. In this sense, they still have several challenges for rural development. The expansion of the policy, associated with systemic analyzes for its constant improvement, is, therefore, a promising path for the economic development of family farming in Brazil.

Keywords: Family agriculture. Rural development. Public policies.

\section{INTRODUÇÃO}

A expansão rural sempre se baseou no pressuposto de que o conhecimento tecnológico, a difusão de novas técnicas agrícolas e o apoio financeiro na forma de empréstimos contribuiriam para aumentar a produção e melhorar as condições de vida no meio rural. É nesse cenário que surge a Política Nacional de Assistência

\footnotetext{
' Médica veterinária. Doutora em melhoramento genético pela Universidade pública de PelotasUFPEL
} 
Técnica e Desenvolvimento Rural para a Agricultura Familiar e Reforma Agropecuária - PNATER, projeto jurídico de iniciativa do Poder Executivo (PL no․ (FIDELIS et al., 2010).

Participar da promoção e animação de processos que possam contribuir para a construção e implementação de estratégias de desenvolvimento sustentável, com foco no desenvolvimento e fortalecimento da agricultura familiar e sua organização, por meio de metodologias educacionais e participativas, integradas às dinâmicas locais, buscando a criação de condições reais para o uso da cidadania e melhoria da qualidade de vida em sociedade (BRASIL, p. 9, 2004).

Para Castro (2005), as empresas prestadoras de assistência técnica e desenvolvimento rural têm a missão de atender às necessidades da agricultura familiar, transferindo conhecimento tecnológico, por meio da utilização de metodologia diversa, com abordagem construtivista para cada realidade do meio rural, primando pela eficiência produtiva e melhoria da qualidade de vida das famílias residentes no meio rural. Dessa forma, a assistência técnica pública e a política de desenvolvimento rural contribuem para a ação institucional que possibilite a implementação e consolidação de uma estratégia de desenvolvimento rural sustentável, capaz de gerar renda e novos empregos. Ainda para este autor, destacam-se como eixos norteadores da política: as bases epistemológicas da agroecologia, o respeito à pluralidade e à diversidade social, econômica, étnica, cultural e ambiental do país, o que implica a necessidade de se incluírem enfoques de gênero, de geração, de raça e de etnia nas orientações de projetos e programas.

Segundo Peixoto (2008), o conceito de ampliação rural pode ser conceituado de três formas distintas: como processo, como instituição e como política. Como processo, a ampliação rural significaria, no sentido literal, o ato de expandir, receber ou transmitir conhecimentos desde a origem de sua produção até o destinatário final, ou seja, a comunidade rural. Porém, como processo, em um sentido mais amplo e agora mais aceito, a expansão rural pode ser entendida como um processo educativo de comunicação de saberes de qualquer natureza, tanto técnicos quanto não técnicos. Ainda para este autor, a expansão rural difere conceitualmente da assistência técnica por não ter necessariamente caráter educacional, pois visa apenas solucionar 
problemas específicos, específicos, sem capacitar o produtor rural. E justamente pelo seu caráter educativo, os serviços de desenvolvimento rural são realizados diariamente por instituições públicas, organizações não governamentais e cooperativas, mas também prestam assistência técnica.

O termo extensão de áreas rurais também pode ser entendido como política pública. Neste caso, estamos nos referindo a uma política de desenvolvimento rural desenvolvida pelos governos (federal, estadual ou municipal) ao longo do tempo, por meio de dispositivos legais ou de software, mas que pode ser implementada por organizações públicas e / ou privadas.

Agricultura familiar é o cultivo e uso da terra por pequenos proprietários, utilizando como mão de obra as pessoas da família do proprietário. Atualmente, a agricultura familiar cobre $85 \%$ dos domicílios rurais, $30 \%$ da terra, 38\% da produção e $77 \%$ das ocupações relacionadas à atividade agrícola. Além disso, é responsável por 60\% da produção de itens básicos da mesa brasileira, como vegetais, feijão, arroz, milho, mandioca, leite e carne (IBGE, 2006).

A agricultura orgânica é um sistema de produção que exclui o uso de fertilizantes sintéticos, pesticidas, reguladores de crescimento, organismos geneticamente modificados e recomenda o uso de esterco animal, rotação de culturas, adubo verde, composto e controle biológico de pragas e doenças. Este sistema de produção está diretamente relacionado com o desenvolvimento sustentável do meio rural, pois introduz uma nova prática no meio rural que privilegia o uso eficiente dos recursos naturais, a preservação da biodiversidade, a proteção do meio ambiente e a qualidade de vida humana.

Os agricultores familiares veem a agricultura orgânica como uma excelente oportunidade para promover seu desenvolvimento econômico e social, pois a expansão do mercado e a redução do uso de insumos externos aliados ao valor agregado dos produtos orgânicos trazem benefícios econômicos por meio de melhorias. esses agricultores (OELOFSE et al., 2010). No Brasil, 90\% da produção orgânica provém da agricultura familiar (IBGE, 2006).

Portanto, pode-se afirmar que a agricultura orgânica é uma forma de sustentabilidade econômica e social para a agricultura familiar, pois busca utilizar 
sistemas agrícolas diversificados, maior densidade de áreas verdes, economia de energia e preservação da biodiversidade. Tudo isso contribui para a manutenção da qualidade de vida dos produtores, suas famílias e consumidores.

No Ceará, sabe-se que a agricultura familiar, assim como no restante do país, é de grande importância para a produção de alimentos orgânicos, pois, de acordo com o censo agropecuário de 2006, 90,5\% das propriedades rurais utilizam a agricultura orgânica ocupando uma área de Até 50 ha. Desses pequenos produtores, 41,6\% possuem propriedades que variam de I a 5 hectares. $O$ número de produtores orgânicos no estado gira em torno de 5.000, dos quais apenas 20\% são certificados (IBGE, 2006).

Para que um produto tenha o rótulo ecológico, ele deve provir de um sistema que tenha aplicado os princípios da legislação ecológica, por um período variável, dependendo do uso anterior da unidade de produção e da situação ecológica atual, por meio de análise e avaliação pelas autoridades de supervisão. $O$ controle de qualidade orgânico visa fornecer ao público a garantia de que os produtos foram produzidos de acordo com as regulamentações sobre sistemas de produção orgânica. Para que os produtos sejam vendidos como orgânicos, eles devem ser controlados por um desses mecanismos.

Os agricultores familiares que comercializam sua produção diretamente e participam de processos próprios de organização e controle social estão isentos de certificação e devem garantir a qualidade dos alimentos orgânicos por meio da Organização de Auditoria Social (OCS) devidamente cadastrada nos órgãos reguladores do governo federal. Como parte do controle social, os produtores devem garantir que os consumidores e órgãos de controle tenham rastreabilidade do produto e livre acesso aos locais de produção. A garantia da qualidade ecológica à luz dos requisitos técnicos legais se dá por meio da relação de confiança, comprometimento e transparência das pessoas envolvidas no processo de geração de credibilidade (BRASIL, 2009).

Os produtores que não se enquadram na modalidade de venda direta e desejam produzir e comercializar orgânicos devem estar cadastrados no Sistema Brasileiro de Avaliação da Conformidade Orgânica (SISORG). Os mecanismos de 
controle de qualidade ecológica reconhecidos pelo SISORG são dois: Sistema de Garantia Participativa (SPG) e Certificação de Auditoria. O SPG é composto por membros do sistema (produtores, trabalhadores, consumidores, técnicos, etc.) e por um Organismo Participante de Avaliação da Conformidade (OPAC), credenciado pelo Ministério da Agricultura, Pecuária e Abastecimento (MAPA), que assume a responsabilidade formal pelo conjunto de atividades desenvolvidas no SPG. Esse sistema é caracterizado por uma relação de confiança na qual os membros compartilham a responsabilidade pelo cumprimento das regulamentações $\mathrm{da}$ produção orgânica (BRASIL, 2009).

A certificação de auditoria, realizada por Organismo de Avaliação da Conformidade $(\mathrm{OAC})$ credenciado, é um procedimento que garante a qualidade de um produto orgânico, certificando que o sistema de produção cumpre as regras da produção orgânica desde a produção até o consumo. Além da certificação individual, um agricultor pode obter a certificação em grupo, desde que faça parte de uma organização formal, como, por exemplo, associações e cooperativas que são estruturadas o suficiente para fornecer um Sistema de Controle Interno (SCI) garantindo que as unidades de produção individuais cumpram os regulamentação da produção orgânica (BRASIL, 2009).

O controle de qualidade orgânico e os mecanismos de informação trazem inúmeros benefícios ao agricultor familiar, incluindo a diferenciação de seus produtos e a garantia ao consumidor de que foram realmente produzidos no sistema orgânico, evitando possíveis fraudes. Para Oliveira et al. (2006) a certificação torna a propriedade mais tecnicamente eficiente, pois requer planejamento e maior controle da produção por parte do produtor. Como forma de identificar e controlar toda a produção orgânica do país, todos os produtos orgânicos brasileiros.

De acordo com o Decreto 6.323, o selo do SISORG não pode ser utilizado para identificação de produto orgânico de agricultores familiares de venda direta, mas esses agricultores podem utilizar no ponto de venda e no rótulo do produto a frase "Produto orgânico para venda direta por agricultores familiares organizados não sujeita a certificação de acordo com a Lei no ${ }^{\circ}$ Io.831, de 23 de dezembro de 2003. " (BRASIL, 2009). 
Mecanismos de controle de qualidade orgânico oferecem inúmeros benefícios e garantias para produtores e consumidores, mas este é um benefício que ainda não está disponível, principalmente para os agricultores familiares. Para Dulley et al. (2003), a certificação não está disponível devido ao custo de obtenção do selo e às dificuldades técnicas e culturais enfrentadas pelos agricultores em cumprir os requisitos técnicos da regulamentação.

O conjunto de normas e regulamentos impostos pelas certificadoras pode ser de difícil interpretação e aplicação pelos agricultores familiares, tornando esse mecanismo de controle indisponível devido à complexidade das etapas necessárias para certificar a produção (MEDAETS; FONSECA, 2005).

Segundo Meira e Candiotto (2011), os sistemas de certificação devem ser flexíveis e se adaptar à realidade familiar dos agricultores. Os autores ressaltam que a organização dos agricultores (associações ou cooperativas) é necessária para o desenvolvimento do movimento ecológico e é necessária para superar os entraves financeiros e tecnológicos imobiliários, bem como para facilitar o acesso aos recursos para a produção e comercialização dos produtos.

Oelofse et al. (2010), realizando três estudos de caso na China e no Brasil, concluíram que a agricultura orgânica requer apoio externo em termos de produção (assistência técnica), certificação e comercialização, e que é necessária uma organização de agricultores para atingir esse tipo de apoio. A Assistência Técnica e Desenvolvimento Rural (ATER) na agricultura familiar pode criar condições objetivas para ajudar os agricultores a superar os obstáculos que encontram, principalmente na certificação e comercialização de produtos orgânicos, contribuindo significativamente para o desenvolvimento da agricultura orgânica.

Vale destacar que a nova Política Nacional de Assistência Técnica e Ampliação Rural para a Agricultura Familiar e Reforma Agrária (PNATER) e o Programa Nacional de Assistência Técnica e Ampliação Rural para a Agricultura Familiar e Reforma Agrária (PRONATER) no Brasil visam estimular e apoiar o rural sustentável iniciativas de desenvolvimento voltadas ao fortalecimento da agricultura familiar, visando à melhoria da qualidade de vida por meio da adoção da 
agricultura orgânica, contribuindo para a segurança alimentar da população (BRASIL, 2010).

Vale destacar que a ATER na agricultura familiar tem se tornado um importante suporte para os agricultores na superação de obstáculos encontrados principalmente na certificação e comercialização de produtos orgânicos, contribuindo significativamente para o desenvolvimento da agricultura orgânica. Diversos agricultores familiares poderão agregar valor à produção orgânica e melhorar sua qualidade de vida por meio de programas de certificação

\section{OBJETIVOS}

Com base no que foi apontado até aqui, delineiam-se os desígnios desta pesquisa, segundo segue.

\section{I.I Objetivo Geral}

Exibir a percepção dos atores da necessidade da Assistência Técnica e Extensão Rural para os produtores de base familiar.

\section{2 Objetivos Específicos}

- Identificar e analisar às precisões da agricultura familiar.

- conhecimento dos programas e certificações da Extensão Rural.

\section{REFERENCIAL TEÓRICO}

Trata-se sobre as atividades de ATER no Brasil, desde os primeiros movimentos até consolidação dos serviços de ATER.

\section{I A assistência técnica e extensão rural no Brasil}

A consolidação das atividades da ATER está diretamente relacionada à demanda da produção agrícola para abastecer a indústria durante a revolução industrial. Vários países passaram por um intenso processo de modernização da agricultura, conhecido como revolução verde, e o papel do agente de ATER tem sido de extrema importância no processo de crescimento do setor agrícola. 
Segundo Castro e Pereira (2014), o surgimento do sistema de atendimento de ATER no Brasil teve início no final da década de 1940, quando foi criada no estado de Minas Gerais, em 1948, a Associação de Crédito e Assistência Rural - ACAR. "Recomendações do empresário americano Nelson Rockefeller ao governo de Minas Gerais para a criação de uma instituição que trabalhasse para melhorar as condições sociais e econômicas de vida no meio rural.

Segundo Oliveira (2012), a ACAR prestava serviços de desenvolvimento rural e elaborava projetos financeiros para obtenção de crédito junto a instituições financeiras. Assim, iniciou-se a oficialização dos serviços de ATER. Conforme mencionado acima, o modelo de serviços de assistência técnica e desenvolvimento rural é baseado no modelo norte-americano (Farmers 'Institutes). Nesse período, o trabalho dos agentes de ATER era de natureza econômica, pois as tecnologias desenvolvidas visavam aumentar a produtividade e a renda da agricultura.

Porém, segundo Oliveira (2012), o ACAR funcionava mais como uma entidade de crédito e não cumpria seu papel de educar os residentes rurais. O objetivo dos serviços de ATER era modernizar a agricultura brasileira, processo conhecido como Resolução Verde. Nesse processo, os agricultores que aplicarem novas tecnologias teriam acesso a empréstimos rurais subsidiados e outros incentivos financeiros para o uso de máquinas e insumos agrícolas. $\mathrm{O}$ mecanismo de ação é muito característico da escola de difusão. A revolução verde teve efeitos negativos sobre o meio ambiente e as relações sociais no campo.

A urgência do aumento da produção agrícola exigiu uma série de inovações tecnológicas que foram concebidas de forma redutora e especializada, ou seja, de toda a complexidade da produção (cultivo, sociedade e meio ambiente), apenas a variável cultivar foi selecionada para modificação. tendo em vista que esta cultura é preferencialmente em monocultura. A agricultura deve crescer independentemente das externalidades negativas geradas para a sociedade e o meio ambiente.

$\mathrm{Na}$ década de 1990, o Brasil passou por uma série de mudanças institucionais e estruturais em meio a uma recessão profunda. $O$ esgotamento do processo de substituição de importações, a crise fiscal e a intensificação do fenômeno da globalização tornaram necessária a estabilização da economia do país. O governo da 
época decidiu aplicar a política do estado mínimo, base central do neoliberalismo32, com as seguintes medidas adotadas: política de renda; reforma administrativa e privatização; reforma tributária; reforma do comércio exterior e reforma monetária (GREMAUD, 2013).

\section{DESENVOLVIMENTO SUSTENTÁVEL RURAL}

Pode-se dizer que o modelo de desenvolvimento rural popularizado durante a Revolução Verde baseava-se na implantação de novas tecnologias na produção agrícola com o objetivo de aumentar os lucros econômicos (produção e renda). O trabalho na agricultura deveria ser altamente especializado, caracterizado pela monocultura com produção em larga escala, voltada para o mercado externo, uso intensivo de agroquímicos e fortemente dependente da indústria, seja do lado da oferta, por meios industrializados ou do lado da demanda, agrícola os produtos são comercializados como matéria-prima para a indústria.

Com o passar dos anos, os efeitos negativos da agricultura convencional começaram a aparecer e se intensificar. A mecanização da agricultura por meio do crédito subsidiado resultou no desemprego no campo, no aumento das desigualdades de renda no meio agrícola e no endividamento de diversos produtores. As políticas públicas para melhorar a vida rural têm contribuído mais para agravar os problemas sociais nas áreas rurais.

$\mathrm{O}$ uso indevido de produtos industrializados tem prejudicado a saúde humana, seja pelo uso de agrotóxicos, seja pelo consumo de alimentos contaminados com agrotóxicos, e tem prejudicado o meio ambiente pela degradação dos recursos naturais. Diante dessa situação, conforme revelado por Oliveira (1999), algumas mudanças seriam necessárias na busca por modelos de produção mais sustentáveis, bem como outras atividades que não puramente agrícolas. Tem havido várias discussões sobre o desenvolvimento sustentável e o setor agrícola começa a pensar em novos modelos de exploração dos recursos naturais cujo modelo de desenvolvimento rural também seja sustentável.

Segundo Assis (2006), o desenvolvimento sustentável é fundamental para a melhoria da qualidade de vida das pessoas, dentro dos limites da capacidade de 
suporte dos ecossistemas, onde as pessoas são as beneficiárias e instrumentos do processo, e seu envolvimento é fundamental para alcançar o sucesso almejado. Segundo o conceito de desenvolvimento sustentável, para alcançá-lo é necessário buscar a harmonia e a racionalidade não só entre o homem e a natureza, mas sobretudo entre as pessoas.

\section{I Contribuição da ATER para a qualidade dos produtos orgânicos}

Embora os produtores tenham conhecimento técnico empírico da produção orgânica, muitos não estavam familiarizados com os regulamentos e adotaram práticas não conformes de forma consistente, dificultando o ajuste de suas propriedades. As reuniões e visitas técnicas foram essenciais para transmitir informações sobre a produção orgânica e regulamentos aos produtores orgânicos, bem como aos produtores que decidiram converter suas áreas convencionais em orgânicos. A assistência técnica prestada valorizou a troca de conhecimentos entre técnicos e produtores rurais e priorizou a tomada de decisões conjuntas.

Desta forma, os agricultores puderam visualizar os ajustes necessários de forma prática e os técnicos puderam adaptar as tecnologias e demonstrar alternativas adequadas à realidade de cada bem para lidar com o não atendimento aos requisitos técnicos da legislação aplicável. Os principais problemas encontrados referem-se ao período de conversão exigido, ao uso de técnicas ou produtos não conformes, ao risco de contaminação de áreas ecológicas ou mesmo à produção de uso próprio, onde a certificação não é necessária.

Ficou claro também que a falta de canais de comercialização de produtos orgânicos, funcionados em muitas regiões, tornou-se um grande obstáculo ao desenvolvimento da agricultura orgânica, desestimulando os agricultores a certificarem sua produção. Em relação à adequação da propriedade e à documentação exigida, constatou-se que a principal dificuldade do produtor era o registro das atividades realizadas na propriedade e o planejamento da produção orgânica. Os produtores questionam a obrigação de manter esses registros ao adotar um sistema orgânico, pois não existe tal exigência para os sistemas de produção convencionais. 
Nesse sentido, a equipe técnica, com o apoio dos agricultores, desenvolveu cadernos de campo para registrar as atividades que tiveram sucesso no mapeamento do uso do solo nas unidades rurais em imagens de sensoriamento remoto. Além de auxiliar na rastreabilidade e no planejamento da produção orgânica, o mapeamento das propriedades tem sido utilizado para o planejamento ambiental da propriedade, identificação das áreas de preservação permanente (APP) e reserva legal (RL) existentes, e para recuperação, possibilitando os impactos ambientais para ser regulamentado.

Era óbvio que a ATER precisava ser certificada pelos produtores porque além da adequação das características, planejamento e rastreabilidade da produção orgânica, documentação como subsídio de água, comprovante do período de conversão, todos os documentos exigidos são exigidos pelo organismo certificador, sem o qual o agricultor não consegue obter orientação técnica adequada.

Para Oliveira (2012), uma das principais dificuldades na produção de alimentos orgânicos é a falta de recursos e capacitação que poderiam ser melhorados por meio de assistência técnica na produção orgânica. Reconhecendo as dificuldades comerciais e sociais enfrentadas pelos agricultores, a certificação orgânica para agricultores atendidos pelo PPCPO, sem a prestação eficiente dos serviços de ATER, seria considerada um obstáculo para a manutenção dessas características no mercado orgânico. Considera-se que as dificuldades encontradas pelos agricultores em cumprir determinados requisitos técnicos da legislação nem sempre estão relacionadas com a falta de adequação, mas sim com a falta de acesso às informações relevantes da ATER.

Portanto, o ATER deve ser executado por técnicos capacitados, que valorizem a troca de conhecimentos e saberes, estejam familiarizados com a realidade da agricultura familiar e estejam preparados para explicar alternativas e adaptar tecnologia a cada tipo de ativo manejado. Embora a certificação orgânica traga muitos benefícios aos produtores e garanta a qualidade dos alimentos orgânicos aos consumidores, uma grande quantidade de documentação e burocracia para atender a todos os requisitos legais e de certificação, juntamente com suporte técnico incerto, podem levar o produtor a optar por não receber a certificação. 
A falta de assistência técnica para atender a padrões rígidos e a complexidade da burocracia combinada com os altos custos da certificação significam que muitos agricultores não precisam auditar a certificação. Era óbvio que havia necessidade de ATER devido a requisitos legais específicos em todas as fases relacionadas com o sistema de produção orgânico. Mesmo após a obtenção da conformidade orgânica, o monitoramento é necessário para subsidiar o produtor com informações técnicas para a continuidade da certificação.

\subsection{Potenciais da agricultura familiar}

A agricultura familiar orgânica tem muitas vantagens para a agricultura familiar, mas a adoção de um mecanismo de controle de qualidade orgânico que visa diversificar os produtos e apoiar a expansão para novos mercados pode se tornar um obstáculo se não houver uma assistência técnica adequada e acessível para esses agricultores. Garantir a qualidade dos produtos orgânicos por meio do controle social é uma alternativa para os pequenos produtores que vendem diretamente e não podem arcar com os custos da certificação.

Além disso, as vendas diretas, sem intermediários, estabelecem preços mais justos, tornando os alimentos orgânicos acessíveis às camadas mais vulneráveis da população. No entanto, muitos produtores ainda desconhecem esse mecanismo de controle e, sem um ATER, não sabem como acessar essa alternativa. A partir do momento em que o produtor e o consumidor se distanciam, há a necessidade de garantir a qualidade do produto orgânico por meio do SGP ou da certificação de auditoria.

O Sistema Participativo de Garantia é caracterizado pela participação de produtores rurais, consumidores, técnicos, comerciantes e todos os compartilhados de poder de decisão sobre conformidade ambiental. Além disso, o OPAC pode fornecer assistência técnica para orientar os fabricantes sobre como corrigir nãoconformidades e como melhorar o sistema de produção e comercialização. No entanto, o funcionamento deste mecanismo é frequentemente desconhecido dos agricultores. O SGP visa não apenas controlar e padronizar os sistemas de produção 
orgânica, mas também fortalecer a agroecologia por meio da troca de conhecimentos e conhecimentos entre os produtores.

Os custos diretos para garantir a qualidade dos produtos orgânicos podem ser menores do que para a certificação de auditoria, mas os custos indiretos relacionados ao tempo despendido por produtores, consumidores e técnicos no SGP, despesas com viagens e assistência técnica para corrigir não conformidades $e$ documentação questionam a sustentabilidade da GSP (ASSIS, 2006).

Por outro lado, a certificação de auditoria não fornece aos produtores qualquer tipo de assistência técnica, como no SPG, o que os impede de contribuir para o desenvolvimento do conhecimento em relação à produção orgânica, pois as certificadoras apenas apresentam não conformidades e não contribuem para as correções necessárias. As enormes dificuldades que os produtores rurais enfrentam para acessar esse mecanismo de controle estão relacionadas à falta de assistência técnica e aos custos da certificação.

Há trabalho administrativo em cada um dos mecanismos de controle, mas no SPG há uma tendência de redução desse trabalho administrativo à medida que produtores e grupos aprendem e ganham autonomia. No caso da certificação, o ônus administrativo é maior, pois a garantia é baseada em registros e documentos. Como alternativa à redução de custos por meio da certificação, estimulando a organização e o desenvolvimento local dos grupos de produtores, está prevista a certificação dos grupos de produtores.

Pesquisas nessa área mostram que os produtores rurais reconhecem e reconhecem que a certificação em grupo pode trazer benefícios e facilitar a manutenção da certificação orgânica. Além disso, fomenta o fortalecimento do cooperativismo e possibilita a troca de experiências entre os agricultores que unem esforços para superar os obstáculos na certificação e comercialização de produtos orgânicos. No entanto, o processo de certificação em grupo torna-se mais complexo à medida que requisitos comuns para a certificação individual e recursos específicos voltados para a certificação em grupo são adicionados.

A complexidade do processo de certificação de auditoria de grupo justifica os serviços da ATER para agilizar este modelo de certificação. . Quando se trata de 
produzir e processar alimentos orgânicos de origem animal, os agricultores enfrentam ainda mais problemas com a certificação. A construção de unidades de processamento adequadas geralmente não é viável para a maioria dos agricultores familiares devido à pequena escala de produção e ao mercado limitado para esse tipo de alimento. Mesmo com a formação adequada, a obtenção de licenças sanitárias e ambientais é um sério obstáculo para a agricultura familiar.

Os serviços de ATER são necessários para promover e integrar a produção pecuária orgânica, vinculados a políticas públicas específicas de apoio e financiamento. Apesar das dificuldades encontradas, o potencial do sistema de produção orgânico como alternativa à agricultura familiar pode ser percebido na medida em que a grande maioria dos agricultores atendidos comercializa seus produtos em mercados institucionais como o Programa de Aquisição de Alimentos (PAA) e a Escola Nacional do Rio de Janeiro. Programa de Alimentação (PNAE), que absorveu parte dessa produção e se tornou catalisador desse padrão de exploração.

Esses mercados são positivos, pois não incentivam a travessia e agregam valor à produção da agricultura familiar. Os valores pagos pelos produtos orgânicos certificados no PAA e PNAE são 30\% superiores aos valores pagos pelos produtos convencionais. Além dos benefícios para os agricultores, a oferta de alimentos orgânicos nesses programas garante que a população mais vulnerável coma alimentos saudáveis e seguros. Para fortalecer essas medidas, é necessário fortalecer algumas políticas públicas que levem em conta a especificidade de cada comuna e grupo de agricultores.

Há perspectivas de atendimento de requisitos tecnológicos específicos para o sistema ecológico, gestão administrativa para integrar a produção e processamento de produtos orgânicos, estratégias de marketing e desenvolvimento e promoção do desenvolvimento rural sustentável. O fortalecimento das associações e cooperativas de produtores é considerado estratégico para superar as barreiras à produção e comercialização; além disso, é fundamental garantir o desenvolvimento da agricultura familiar orgânica. 


\subsection{Política Nacional de Assistência Técnica e Extensão Rural - Pnater}

Em 2003, o Ministério do Desenvolvimento Agrário - MDA assumiu a responsabilidade pela operacionalização da Assistência Técnica e Desenvolvimento Rural - Ater, instituída pelo decreto no 4739, de 13 de junho deste ano. Um grupo de técnicos delegados pela Secretaria de Agricultura Familiar - SAF coordenou a elaboração da nova Política Nacional de Assistência Técnica e Desenvolvimento Rural - Pnater, promovendo um amplo processo de consulta com base em audiências, reuniões e seminários com representantes de agricultores familiares, movimentos sociais e prestadores de serviços I9 Governo e ONGs.

Em setembro de 2003 , foi realizado em Brasília um workshop nacional sobre o desenvolvimento do Pnater. Segundo o Ministério do Desenvolvimento Agrário (BRASIL, 2004), esse processo democrático e participativo envolvendo mais de roo entidades e mais de 500 pessoas levou à construção de alguns consensos e de um conjunto de acordos e resultou em um documento de síntese do Pnater.

O documento final, resultado dos seminários regionais e do seminário nacional em Brasília e da elaboração do Grupo de Trabalho criado para coordenar a construção da nova política, apresentado como o novo Pnater (Ibid, 2004), propõe uma ampla reformulação dos serviços no país, fortalece seu caráter público e gratuito ao grupo de agricultores familiares, estabelece um novo caráter institucional da gestão do sistema nacional de Ater e propõe uma revisão da atuação profissional dos auxiliares. Além disso, elege a agroecologia como "orientadora do eixo de ação".

No início do segundo semestre de 2009, o Poder Executivo encaminhou ao Congresso Nacional projeto de lei que institui o Pnater, cria o Programa Nacional de Assistência Técnica e Desenvolvimento Rural na Agricultura Familiar e Reforma Agropecuária - PRONATER, e dá outras providências. Em Is de dezembro de 2009, a Lei Deputada foi aprovada pelo Senado Federal sem alterações, portanto a matéria foi sancionada.

Finalmente, em II de janeiro de 20I0, o presidente aprovou a Lei de Ater. A Lei Ater institui o Pnater e o Pronater, além da alteração da Lei no 8.666, de 2i de junho de 1993 e dá outras providências. Por isso, foi estabelecido como o principal instrumento de implantação do Pnater e do Pronater. Nos termos da Lei, a 
assistência técnica e o desenvolvimento rural são entendidos como: Serviço educacional informal e contínuo no meio rural, que promove os processos de gestão, produção, beneficiamento e comercialização das atividades e serviços agrícolas e não agrícolas, incluindo a agro-mineração, atividades florestais e artesanais (BRASIL, 2010)

\subsection{Aspectos teóricos da assistência técnica ao agricultor familiar}

No início do século 20, os Estados Unidos institucionalizaram a campanha de expansão rural pela primeira vez na história. Desde então, pesquisas têm sido realizadas para vincular esses serviços ao desenvolvimento rural. Duas teorias são amplamente discutidas no quadro teórico em torno do debate sobre a importância da assistência técnica para o desenvolvimento rural: a teoria da agricultura de alto insumo e a teoria da mudança tecnológica induzida. Ambos defendem a modernização da agricultura, divorciando-a do conceito de agricultura tradicional.

A teoria da agricultura de alto insumo, atribuída a Schultz (1965), define os agricultores como racionais e eficientes em termos de recursos, e as dificuldades de acesso a serviços técnicos e econômicos são um grande obstáculo ao desenvolvimento rural. Em consonância com essa percepção, o acesso à capacitação seria o instrumento básico para o aumento da produtividade nas empresas agrícolas. Ruttan e Hayami (1984), baseados na teoria da Mudança Tecnológica Induzida, completam essa discussão enfatizando que o progresso tecnológico é responsável por substituir fatores de produção escassos por fatores abundantes.

Portanto, o último conceito coloca uma forte ênfase na identificação e difusão da tecnologia como um caminho para o desenvolvimento rural (Gomes et al., 2016). Ao discutir a importância da formação técnica para o desenvolvimento rural, essas teorias destacam o termo expansão rural como um fator crítico para o progresso econômico da agricultura familiar. O conceito de alargamento rural é muito complexo, uma vez que pode ser conceptualizado de três formas diferentes: como processo, como instituição e como política.

A primeira forma se refere ao sentido literal, ou seja, o processo de transferência do conhecimento da fonte geradora para o destinatário rural 
(destinatário final). A percepção do desenvolvimento rural como uma instituição adotando a noção de Schumpter das instituições como órgãos - diz respeito às organizações estatais que prestam assistência técnica e serviços de desenvolvimento rural. Por fim, ao nos referirmos ao conceito de política pública, estamos tratando de serviços de ATER, definidos como políticas desenvolvidas por três esferas de poder (federal, estadual e municipal) que podem ser implementadas por organizações privadas e / ou públicas (Peixoto, 2008).

\section{METODOLOGIA}

Com a finalidade de evidenciar a necessidade da Assistência Técnica e Extensão Rural para os produtores de base familiar trabalhadores rurais, foi feito uma pesquisa bibliográfica. Por meio da pesquisa bibliográfica foi possível avaliar importância. Foi realizado um método de pesquisa de natureza qualitativa, com apoio de revisão de literatura nacional e internacional, empregando os bancos de dados SCIELO, a partir da pesquisa e revisão bibliográfica realizadas, foi plausível descobrir a necessidade os produtores de base familiar têm além dos conceitos através das informações adquiridas no decorrer do trabalho, foi exposto informações, assim como orientações.

\section{RESULTADOS}

O Resultado desta pesquisa teve como objetivo analisar o cenário dos produtores de base familiar trabalhadores do meio Rural foi realizado um levantamento de dados e documentos relevantes ao tema, bem como uma abordagem de autores de importante relevância para o desenvolvimento da pesquisa.

\section{CONCLUSÃO}

$\mathrm{O}$ artigo apresenta um cenário dos produtores familiares atuantes no meio rural, suas dimensões econômica, social e ambiental, bem como sua participação e acesso às políticas públicas como forma de promover o desenvolvimento sustentável do meio rural. Muito progresso foi feito. No entanto, ainda existem muitos desafios no desenvolvimento rural. O desenvolvimento da certificação de sistemas de 
produção orgânica a preços acessíveis para garantir a credibilidade desses produtos no mercado consumidor é uma demanda estratégica fundamental para consolidar o potencial da agricultura para o desenvolvimento da agricultura familiar.

Ressalta-se a necessidade de estender os serviços de ATER para atender a esses requisitos e estender a certificação na agricultura familiar. É de extrema importância estimular programas governamentais de apoio aos agricultores familiares para o cumprimento das regulamentações ecológicas. Por fim, afirma-se que a política de ATER é um poderoso instrumento de geração de renda no Brasil. Vale ressaltar também que a utilização de assistência técnica pelos agricultores familiares impacta outras dimensões não analisadas neste estudo. A expansão da política, aliada à análise de sistemas para melhoria contínua, é, portanto, um caminho promissor para o desenvolvimento econômico da agricultura familiar no Brasil.

\section{REFERÊNCIAS}

BRASIL, Ministério do Desenvolvimento Agrário. Política Nacional de Assistência Técnica e Extensão Rural. Brasília: MDA/SAF/Dater, 2004.

BRASIL. Legislação para os sistemas orgânicos de produção animal e vegetal. Ministério da Agricultura, Pecuária e Abastecimento. Secretaria de Desenvolvimento Agropecuário e Cooperativismo. Brasília: Mapa/ACS, 2009.

BRASIL. Lei №. 12.188 de II de janeiro de 2010. Disponível em http://www.planalto.gov.br/ccivil_03/_Ato2007-2010/2010/Lei/ Li2188.htm. Acesso em i7/or/ 2022.

CASTRO, C.E.F. de. A Pesquisa em Agricultura Familiar. In: CASTRO, et. al. Pontes para o Futuro. $\mathrm{I}^{\mathrm{a}}$ ed. Campinas: CONSEPA, 2005. p.7-48.

CASTRO NETO, N.; DENUZI, V.S.S.; RINALDI, R.N.; STADUTO, J.A.R. Produção Orgânica: um potencial estratégico para a agricultura familiar. Revista Percursos, Maringá, vol. 2, n. 2, 2010.

DULLEY, R.D.; SILVA, V.; ANDRADE, J.P.S Estrutura Produtiva e Adequação ao Sistema de Produção Orgânico. Informações Econômicas, São Paulo, vol. 33, n. II, 2003.

FIDELIS, L. M; BERGAMASCO, S. M. P. P; LOPES, D. G; RODRIGUES, T. R. I. A Nova Pnater: Uma Análise de sua Tramitação pelo Congresso Nacional. $4^{\underline{o}}$ 
Encontro da rede de estudos rurais. Mundo Rural, Políticas Públicas, Instituições e Atores em Reconhecimento Político. Curitiba - PR, julho, 2010, p. 2-3.

GREMAUD, A. P. Economia Brasileira. Instituto de Gestão, Economia e Políticas Públicas - IGEPP. ago. 2013. Disponível em: . Acesso em 17/or/2022.

INSTITUTO BRASILEIRO DE GEOGRAFIA E ESTATÍSTICA. Censo agropecuário: agricultura familiar primeiros resultados. IBGE: Rio de Janeiro, 2006. (Versão digital: SIDRA).

Instituto Brasileiro de Geografia e Estatística - IBGE. (2006). Censo Agropecuário 2006. Rio de Janeiro: IBGE.

MEDAETS, J.P.; FONSECA, M.F.A. Produção orgânica: regulamentação nacional e internacional. Brasília: PCT/MDA//IICA, 2005.

MEIRA, S.G.; CANDIOTTO, L.Z.P. A organização de produtores nos municípios de Francisco Beltrão e de Verê - PR para a comercialização de alimentos orgânicos. Revista de Geografia (UFPE) vol. 28, n. I, 2011.

OELOFSE, M.; HONG-JENSEN, H.; ABREU, L.S.; ALMEIDA, G.F.; HUI, Q.Y.; SULTAN, T. Certified organic agriculture in China and Brazil: Market accessibility and outcomes following adoption. Elsevier. EcologicalEconomics, vol. 69, n. 9, 2010.

OLIVEIRA, R.A.; LIMA, P.S.; SILVA, L.M.R. O consumo e comercialização de produtos orgânicos: o caso da associação para o desenvolvimento da agropecuária orgânica. In: CONGRESSO DA SOCIEDADE BRASILEIRA DE ECONOMIA, ADMINISTRAÇÃO E SOCIOLOGIA-RURAL, 44. Fortaleza: SOBER, 2006.

Oliveira, M. M. (1999). As circunstâncias da criação da extensão rural no Brasil. Cadernos de Ciência \& Tecnologia, 16(2), 97-134.

PEIXOTO, M. Extensão Rural no Brasil - uma abordagem histórica na legislação. Textos para discussão, Brasília, DF: outubro/2008.

Peixoto, M. (2008). Extensão rural no Brasil - uma abordagem histórica da legislação (pp. I-5o). Brasília: Núcleo de Estudos e pesquisas do Senado.

Pereira, S. (2004). Avaliação da Política de Agricultura Familiar: uma abordagem de efeito-fixo. In Anais do XVII Congresso da SOBER. Brasília: SOBER. 